\title{
Glutamate Spillover between Mammalian Cone Photoreceptors
}

\author{
Brett A. Szmajda and Steven H. DeVries \\ Department of Ophthalmology, Northwestern University Feinberg School of Medicine, Chicago, Illinois 60611
}

Cone photoreceptors transmit signals at high temporal frequencies and mediate fine spatial vision. High-frequency transmission requires a high rate of glutamate release, which could promote spillover to neighboring cells, whereas spatial vision requires that cones within a tightly packed array signal light to postsynaptic bipolar cells with minimal crosstalk. Glutamate spread from the cone terminal is thought to be limited by presynaptic transporters and nearby glial processes. In addition, there is no ultrastructural evidence for chemical synapses between mammalian cones, although such synapses have been described in lower vertebrate retinas. We tested for cone-cone glutamate diffusion by recording from adjacent cone pairs in the ground squirrel retina, and instead found that the glutamate released by one cone during electrical stimulation activates glutamate transporter $\mathrm{Cl}^{-} \mathrm{conduc}^{-}$ tances on neighboring cones. Unlike in other systems, where crosstalk is diminished by increasing the temperature and by moving to a more intact preparation, glutamate spread persisted at physiological temperatures $\left(37^{\circ} \mathrm{C}\right)$ and in retinal flat mounts. The glutamate-gated anion conductance in cones has a reversal potential of $\sim-30 \mathrm{mV}$ compared with a cone resting potential of $\sim-50 \mathrm{mV}$; thus, crosstalk should have a depolarizing effect on the cone network. Cone-cone glutamate spread is regulated by the physiological stimulus, light, and under physiological conditions can produce a response of $\sim 2 \mathrm{mV}$, equivalent to $13-20 \%$ of a cone's light response. We conclude that in the absence of discrete chemical synapses, glutamate flows between cones during a light response and may mediate a spatially distributed positive feedback.

\section{Introduction}

Form vision relies on two types of photoreceptors: rods, which operate in dim light, and cones, which operate in bright light. Individual cones can transduce high temporal frequencies (up to $100 \mathrm{~Hz}$ ), while arrays of cones can encode high spatial frequencies (up to 2 cycles per minute of arc). To transmit high temporal frequencies to postsynaptic bipolar cells, a cone must maintain a high rate of transmitter release. Individual cones release the neurotransmitter glutamate at steady rates of $100-1000$ vesicles-s $^{-1}$, attaining instantaneous rates during light-to-dark transitions of $2-3 \times 10^{4}$ vesicles-s ${ }^{-1}$ (i.e., $400-$ 600 docked vesicles released over $\sim 5 \mathrm{~ms}$ ) (DeVries et al., 2006; Jackman et al., 2009). This ability to signal high temporal frequencies comes at a potential cost: large amounts of released transmitter could flood the synapse, leading to a spillover of glutamate to adjacent cells. This glutamate could activate transporter $\mathrm{Cl}^{-}$conductances on neighboring cones (Sarantis et al., 1988; Tachibana and Kaneko, 1988; Picaud et al., 1995a), and ionotropic (Slaughter and Miller, 1983) or

\footnotetext{
Received April 27, 2011; revised July 21, 2011; accepted July 29, 2011.

Author contributions: B.A.S. and S.H.D. designed research; B.A.S. and S.H.D. performed research; B.A.S. and S.H.D. analyzed data; B.A.S. and S.H.D. wrote the paper.

This work was supported by NIH Grant EY012141 and Research to Prevent Blindness. We thank Dr. Jun Shi and Elizabeth Cowan for technical help.

The authors declare no financial conflicts of interest.

Correspondence should be addressed to Steven H. DeVries, Department of Ophthalmology, Tarry 5-713, Northwestern University Feinberg School of Medicine, Chicago, Illinois 60611. E-mail: s-devries@northwestern.edu.

DOI:10.1523/JNEUROSCI.2105-11.2011

Copyright $\odot 2011$ the authors $\quad 0270-6474 / 11 / 3113431-11 \$ 15.00 / 0$
}

metabotropic (Nakajima et al., 1993) glutamate receptors on their postsynaptic bipolar cells, thus reducing the independence of adjacent visual channels.

Crosstalk between cone terminals is thought to be minimized by two mechanisms. First, processes from approximately three Muller glial cells ensheath a cone terminal, forming a physical barrier (Burris et al., 2002) that also contains glutamate transporters (Sarthy et al., 2005). However, cone transmitter may spread beneath terminals in the outer plexiform layer (OPL), where the sheath-like endings have not yet expanded from narrow, ascending Muller cell trunks (Burris et al., 2002, their Fig. 8). Second, released glutamate is captured by transporters that are located on rod and cone terminals (Picaud et al., 1995b; Hasegawa et al., 2006; Rowan et al., 2010). Mouse rods, which release glutamate from one to four synaptic ribbons, recapture all of their released glutamate (Hasegawa et al., 2006). The extent of recapture by cone terminals has not been studied; however, cone terminals contain more ribbons $(20-40)$ and docked vesicles than rod terminals (Dowling and Boycott, 1966; West and Dowling, 1975; Calkins et al., 1996; Chun et al., 1996; Sterling and Matthews, 2005), and thus glutamate release might exceed the sequestering capacity of cone transporters.

We show that, in the mammalian retina, the glutamate released by one cone can flow to neighboring cones and activate a transporter $\mathrm{Cl}^{-}$conductance. Spillover occurs because the amount of glutamate released by a cone saturates uptake mechanisms at the cone terminal, and is evidently able to circumvent the glial barrier between cones. The spillover $\mathrm{Cl}^{-}$current is mod- 
ulated by light, and has an excitatory effect due to a relatively depolarized reversal potential.

\section{Materials and Methods}

Preparation and electrophysiology. All procedures were approved by the Northwestern University Animal Care and Use Committee. The procedure for making ground squirrel (of either sex, Ictidomys tridecemlineatus, formerly Spermophilus tridecemlineatus; Helgen et al., 2009) retinal slices has been described (DeVries and Schwartz, 1999). We used a similar approach to make flat-mount recordings: Retinas were removed from the eyes of killed ground squirrels, cut into $3 \times 3 \mathrm{~mm}$ squares, and placed vitreal side down on a piece of filter paper that contained a central $1.5 \mathrm{~mm}$ diameter hole (catalog no. SSWP02500; Millipore). For experiments involving light responses, both retinal slices and flat mounts were dissected under dim red illumination. Tissue was then transferred to a recording chamber and warmed to either 32 or $37^{\circ} \mathrm{C}$ before recording.

The external solution contained the following (in mM): $\mathrm{NaCl} 115, \mathrm{KCl}$ 3.1, $\mathrm{MgSO}_{4}$ 2.48, glucose 6, Na-succinate 1, Na-malate 1, Na-lactate 1, $\mathrm{Na}$-pyruvate $1, \mathrm{CaCl}_{2} 2, \mathrm{NaHCO}_{3} 25$. For measuring $\mathrm{Ca}^{2+}$ currents, external $\mathrm{Ca}^{2+}$ was replaced with $\mathrm{Cd}^{2+}$. For measuring the effects of ion substitution on the glutamate transporter, external $\mathrm{Na}^{+}$was replaced with $\mathrm{Cs}^{+}$and external $\mathrm{Cl}^{-}$was replaced with $\mathrm{NO}_{3}^{-}$. External solutions were continuously bubbled with $95 \% \mathrm{O}_{2} / 5 \% \mathrm{CO}_{2}$ and the recording chamber was superfused at a rate of $\sim 0.2 \mathrm{ml} / \mathrm{min}$. Cone-cone signaling was isolated by adding picrotoxin $(50 \mu \mathrm{M})$, strychnine $(10 \mu \mathrm{M})$, and 6-cyano-7-nitroquinoxaline-2,3-dione (CNQX, $25 \mu \mathrm{m}$; Tocris Bioscience) to the external solution. Where indicated, D-(-)-2-amino-4phosphonobutyric acid (APB, $50 \mu \mathrm{M})$, a metabotropic receptor agonist, was also added to the external medium. The basic internal solution was (in mM): $\mathrm{KCl} \mathrm{130,} \mathrm{Cs-EGTA} \mathrm{10,} \mathrm{MgSO}_{4} 2$, HEPES buffer 10, ATP 5, and GTP 0.5. To increase the inward current gated by glutamate, $130 \mathrm{~mm}$ KSCN was substituted for $\mathrm{KCl}$. To adjust the $\mathrm{Cl}^{-}$reversal potential to $-30 \mathrm{mV}$ and reduce cone potassium currents, potassium methylsulfonate $(90 \mathrm{~mm})$ and $\mathrm{CsCl}(40 \mathrm{~mm})$ was substituted for $\mathrm{KCl}$. Both internal and external solutions were corrected to a $\mathrm{pH}$ of $7.40 \pm 0.05$ and an osmolarity of $285 \pm 5 \mathrm{mOsm}$. For perforated patch recordings, a stock solution of $10 \mathrm{mg} / \mathrm{ml}$ gramicidin $\mathrm{D}$ in methanol was prepared fresh every $2 \mathrm{~h}$ (Akaike, 1996). This stock solution was diluted into the KCl-based pipette solution to give a final concentration of $0.1 \mathrm{mg} / \mathrm{ml}$, and sonicated for $30 \mathrm{~s}$ to ensure thorough mixing. DL-threo- $\beta$-benzyloxyaspartic acid (TBOA) and L-(-)-threo-3-hydroxyaspartic acid (THA) were obtained from Tocris Bioscience. The fluorescent tracers sulforhodamine 101 and BODIPY 492/515 were obtained from Invitrogen. All chemicals were obtained from Sigma-Aldrich unless otherwise indicated. Membrane voltages were corrected for liquid junction potentials.

Retinal slices were visualized with a Zeiss Axioskop-2 microscope under infrared illumination. Recordings were made with Axopatch 200B amplifiers (Molecular Devices), and signals were filtered at $5 \mathrm{kHz}$ and digitized at a rate of $10 \mathrm{kHz}$ with a ITC-18 A/D board (HEKA Elektronik) operated with custom software (ACLAMP; Igor Pro 6.1; Wavemetrics). Retinas were stimulated with light from an HBO-100 arc lamp (Zeiss) that was passed through a $570 \pm 10 \mathrm{~nm}$ filter or by light-emitting diodes (468 and $574 \mathrm{~nm}$ ) attached to a microscope video port. The arc lamp intensity was attenuated with neutral density filters, while LED intensity was controlled by pulse-width modulation, and could be varied over a 100 -fold range. Light sources were calibrated with a photodiode detector (International Light) that was positioned beneath the microscope objective. The maximal light intensity was $8.1 \times 10^{6}$ photons- $\mu \mathrm{m}^{-2}-\mathrm{s}^{-1}(500$ $\mathrm{nm}$ equivalent) for the $574 \mathrm{~nm}$ diode and $1.9 \times 10^{6}$ photons- $\mu \mathrm{m}^{-2}-\mathrm{s}^{-1}$ for the arc lamp. For comparison, a flash that delivers $1.1 \times 10^{4}$ photons$\mu \mathrm{m}^{-2}$ produces a half-maximal response in ground squirrel cones (Kraft, 1988).

Modeling of acceptor cone responses. Following a brief pulse depolarization, transmitter release from a cone was assumed to occur at a single point followed by diffusion in a hemisphere. The concentration of glutamate as a function of time and distance from the release site is given by

$$
C(t)=\frac{N}{\left(4 \pi D\left(t-t_{0}\right)\right)^{3 / 2}} e^{-r^{2} / 4 D t}
$$

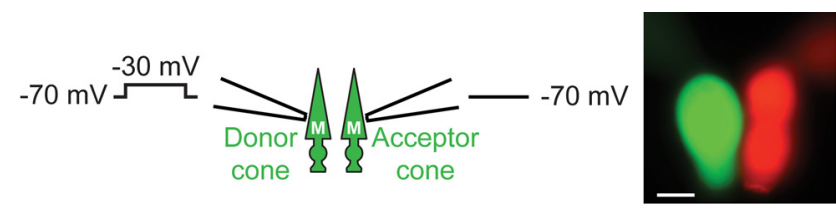

A

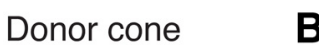

B Acceptor cone
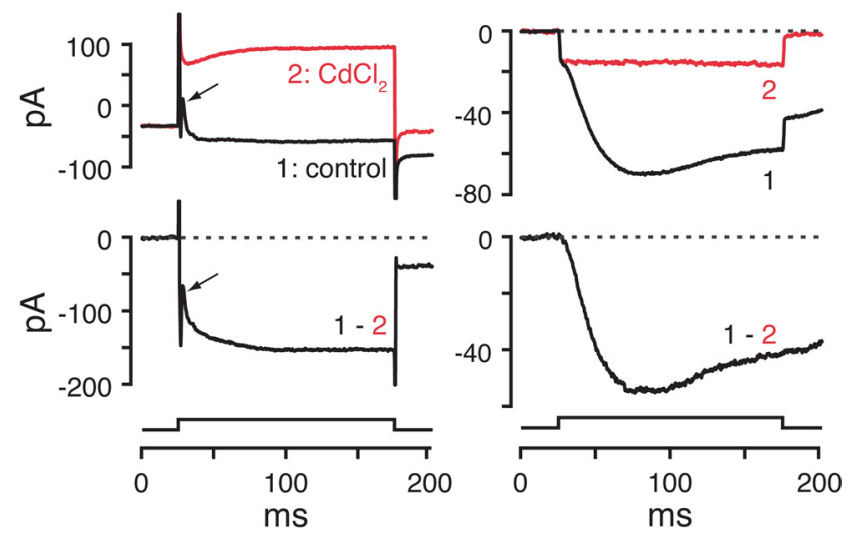

Figure 1. $\quad \mathrm{Ca}^{2+}$-dependent transmission between neighboring cone photoreceptors. Top left, Diagram of the recording configuration. Top right, Fluorescence micrograph of the recorded cone pair. A, Top, Membrane current under control conditions (black trace) and when the $\mathrm{Ca}^{2+}$ current was blocked by adding $1 \mathrm{~mm} \mathrm{CdCl}$ to the external solution (red trace). Bottom, Difference current. Arrows indicate a transient suppression of the $\mathrm{Ca}^{2+}$ current caused by exocytosed protons. $\boldsymbol{B}$, Top, Response in the acceptor (nonstimulated) cone during the donor cone step under control conditions (black trace) and in the $\mathrm{Cd}^{2+}$-containing solution (red trace). Bottom, Difference current. Scale bar: $5 \mu \mathrm{m}$. Pipette solutions contained $10 \mu \mathrm{m}$ of either sulforhodamine 101 (red fluorescence) or BODIPY 492/515 (green fluorescence).

where $t_{0}$ is the time of transmitter release in the donor cone, $N$ scales the amplitude, $r$ is the radial distance between the release site and a small patch of transporters, and $C(t)$ represents the time-dependent transmitter concentration at the location of the transporters. $D$, a diffusion constant, equals $0.33 \mu \mathrm{m}^{2}-\mathrm{s}^{-1}$ (Nielsen et al., 2004).

The cone transporter response to a brief pulse was measured during rapid perfusion experiments in which glutamate-containing $(1 \mathrm{mM})$ and control solutions flowed through adjacent barrels of a double-barreled pipette that was mounted on a piezoelectric translator (Burleigh Instruments) (for additional details, see DeVries et al., 2006). Transporter current increased with a time constant, $\tau$, of $1.6 \mathrm{~ms}$ at the start of the pulse and decayed with a $\tau$ of $\sim 400 \mathrm{~ms}$ after the pulse (see Results, below, and Fig. $3 D)$. Thus, in response to a brief pulse $(<10 \mathrm{~ms})$ of glutamate release from a donor cone, the transporter current is assumed to integrate the local glutamate concentration time course. Consequently, the local glutamate concentration time course can be obtained and modeled by differentiating the initial phase of the transporter response.

Immunohistochemistry. The methods and techniques for antibody staining have been previously described ( $\mathrm{Li}$ et al., 2004). Slice or flatmounted tissue was fixed in $4 \%$ paraformaldehyde for $0.25-2 \mathrm{~h}$, and then labeled with either S-opsin (1:500; Millipore) or ribeye (CtBP2, 1:200; BD Biosciences). Cones were labeled for histology by including $10 \mu \mathrm{M}$ Neurobiotin (Vector Laboratories) in the pipette solution. Images were obtained with a Zeiss LSM 510 confocal microscope using a $63 \times(1.4$ $\mathrm{NA})$ or $100 \times(1.45 \mathrm{NA})$ oil-immersion lens. Image brightness and contrast were adjusted using Adobe Photoshop CS3 (Adobe).

\section{Results}

\section{Mechanism of cone-cone chemical transmission}

We studied cone-cone chemical transmission by recording from pairs of adjacent cones in slices from the ground squirrel retina (Fig. 1). In a typical experiment, the membrane voltages of both cones were initially maintained at $-70 \mathrm{mV}$. The membrane voltage of one cone, hereafter referred to as the donor cone, was then 
stepped to $-30 \mathrm{mV}$, eliciting an inward $\mathrm{Ca}^{2+}$ current that was blocked by $1 \mathrm{~mm} \mathrm{Cd}^{2+}$ (Fig. 1). The step also evoked exocytosis from the donor cone, as shown by the accompanying proton block of the $\mathrm{Ca}^{2+}$ current (Fig. $1 \mathrm{~A}$, arrows) (DeVries, 2001). The membrane current in the acceptor (i.e., unstimulated) cone increased in two phases under control conditions (Fig. 1B, top, black trace): an initial rapid phase and a later slower phase. The initial rapid increase was $\mathrm{Cd}^{2+}$-insensitive and represents gapjunction communication between middle wavelength sensitive (M)-cones (DeVries et al., 2002; Li and DeVries, 2004). The slower component, isolated by subtracting the faster $\mathrm{Cd}^{2+}$. insensitive component, was produced by a $\mathrm{Ca}^{2+}$-dependent process, which is presumably transmitter release evoked by depolarizing the donor cone. We obtained similar results in five additional cone pairs.

We next showed that the slow current in the acceptor cone is mediated by a glutamate transporter $\mathrm{Cl}^{-}$conductance. Like glutamate transport, the transporter $\mathrm{Cl}^{-}$current is blocked by removing external $\mathrm{Na}^{+}$and by competitive antagonists such as THA and TBOA (for review, see Danbolt, 2001). We tested for a dependence on external $\mathrm{Na}^{+}$by stepping a donor cone from -70 to $-30 \mathrm{mV}$ to produce transmitter release while holding the acceptor cone membrane at steady voltages between -70 and +30 $\mathrm{mV}$, both in the presence and absence of external $\mathrm{Na}^{+}\left(\mathrm{Cs}^{+}\right.$ substitution; Fig. $2 A, B$ ). In these experiments, the $\mathrm{Cl}^{-}$reversal potential was set to $0 \mathrm{mV}$. Removing external $\mathrm{Na}^{+}$reversibly abolished the current in the acceptor cone $(n=7$ pairs; Fig. $2 A, B)$ without affecting the proton block that accompanies transmitter release ( $n=4$ pairs) (DeVries, 2001). Plots of peak current versus acceptor cone membrane potential showed inward rectification with a reversal potential close to $0 \mathrm{mV}$ (Fig. $2 B)$. THA $(100 \mu \mathrm{M})$, a nonspecific blocker of excitatory amino acid transporters (EAATs), eliminated the acceptor cone current $(n=5$ pairs; Fig. $2 C, D)$. The effects of this relatively high concentration of THA ( $\mathrm{IC}_{50}$ of THA, $\sim 2.5 \mu \mathrm{M}$ ) (Nakamura et al., 1993) were irreversible following the prolonged applications required to obtain current versus voltage plots, but reversible when briefly applied during measurements at a single acceptor cone holding potential ( $n=5$ pairs). THA did not affect the $\mathrm{Ca}^{2+}$ current in donor cones $(n=2)$. Puffer application of TBOA (210 $\mu \mathrm{M}$ ) caused a similar effect to application of THA [an $81.4 \pm$ $10.1 \%$ decrease in donor (see below) and acceptor response amplitudes compared with control; $n=16]$. Finally, we tested whether a metabotropic glutamate receptor might mediate part of the acceptor cone response by applying the agonist APB (200 $\mu \mathrm{M})$. APB modulates an L-type $\mathrm{Ca}^{2+}$ current in salamander cones (Hosoi et al., 2005). APB had no effect on cone-cone chemical transmission $(0.2 \pm 6.3 \%$ decrease, mean $\pm \mathrm{SD} ; n=3)$. The requirement for external $\mathrm{Na}^{+}$, the block by THA and TBOA, and the rectifying current-voltage relationship are all characteristic of transporters in the EAAT family.

We verified that the donor cone transmitter activated an anion conductance by replacing external $\mathrm{Cl}^{-}$with the more permanent $\mathrm{NO}_{3}^{-}$anion (Fig. $2 E, F$ ). An external solution containing $\mathrm{NO}_{3}^{-}$increased outward current at depolarized acceptor cone potentials and shifted the current reversal potential by $-28.8 \pm$ $6.3 \mathrm{mV}$ ( $n=3$ pairs). Two additional pairs showed a similar result, but the precise shift could not be accurately measured due to large gap-junction currents. The results are consistent with the greater permeability of $\mathrm{NO}_{3}^{-}$relative to $\mathrm{Cl}^{-}$at glutamate transporter anion conductances (Eliasof et al., 1998). Thus, donor cone depolarization leads to the $\mathrm{Ca}^{2+}$-dependent release of glutamate, which activates a transporter anion conductance on
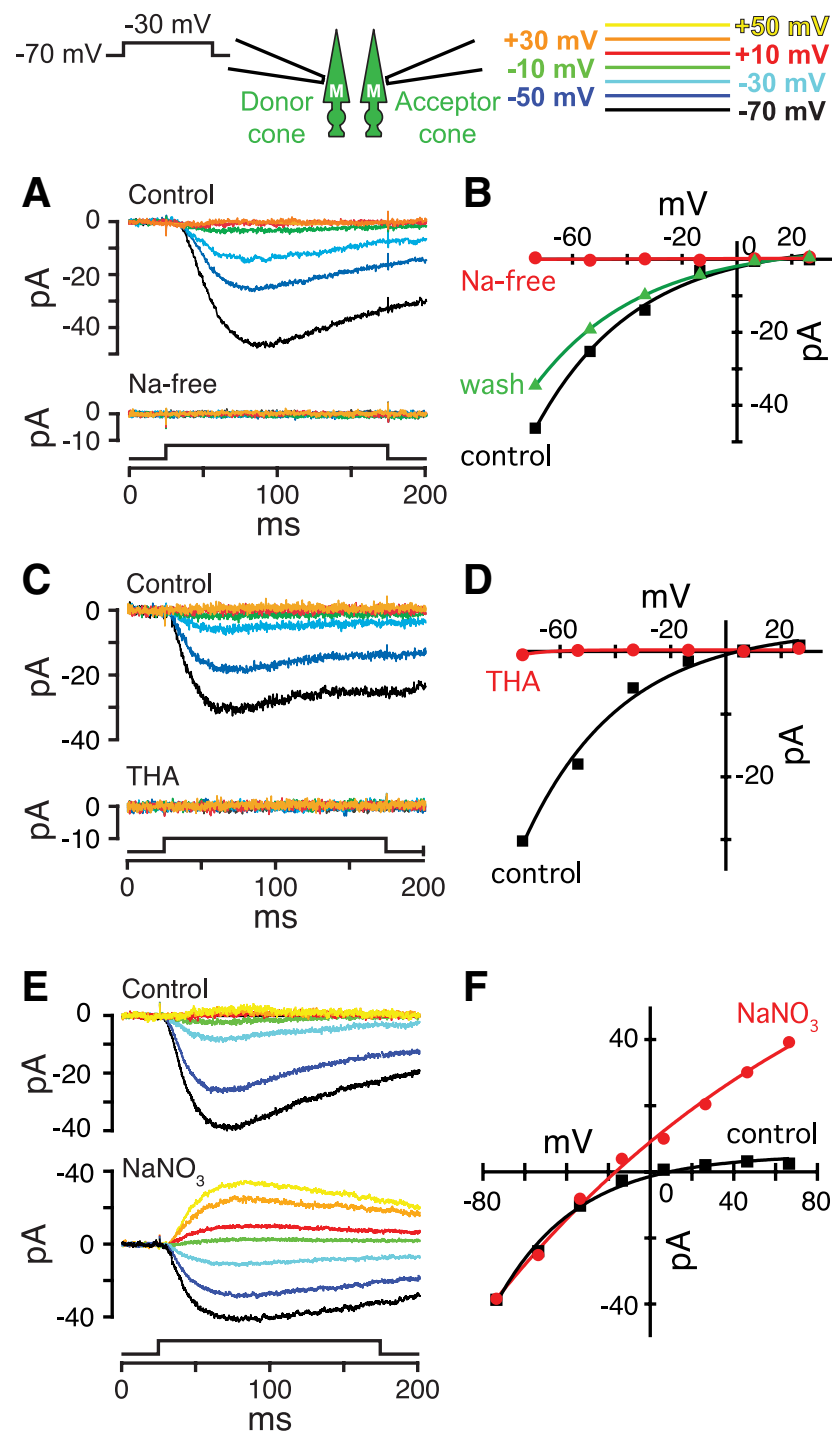

Figure 2. Glutamate activates a transporter anion conductance on adjacent cones. Top left, Recording configuration. Donor cone membrane voltage was held at -70 and stepped to -30 $\mathrm{mV}$. Acceptor cone membrane voltage was held steady at voltages between -70 and $+50 \mathrm{mV}$. Only acceptor cone currents are shown. $\boldsymbol{A}$, Acceptor cone currents before (top) and during (bottom) the substitution of external $\mathrm{Na}^{+}$with $\mathrm{Cs}^{+}$. B, Plot of peak acceptor cone current versus acceptor cone membrane potential before, during, and after exposure to $\mathrm{Na}^{+}$-free solution (same pair as in $A$ ). Data points were fitted with an exponential curve. C, Acceptor cone currents before (top) and during (bottom) puffer application of THA $(100 \mu \mathrm{M})$. D, Peak acceptor cone current versus acceptor cone membrane potential in control and THA-containing solutions (same pair as in $\boldsymbol{C}$ ). $\boldsymbol{E}$, Acceptor cone responses in $\mathrm{Cl}^{-}$-containing extracellular solution (top) and in a solution where $\mathrm{NO}_{3}^{-}$was substituted for $\mathrm{Cl}^{-}$(bottom). For clarity, not all traces are shown. $\boldsymbol{F}$, Peak current-voltage responses obtained from $\boldsymbol{E}$. In these experiments, the junctional conductance was small and no additional blockers were required.

neighboring cones (Sarantis et al., 1988; Tachibana and Kaneko, 1988; Picaud et al., 1995b). Veruki et al. (2006) report a similar crosstalk between rat rod bipolar cell terminals.

Next, we determined whether the time course of the acceptor cone response was consistent with glutamate diffusion from the donor cone. We first needed to exclude the possibility that the slow response in the acceptor cone might result from charging of the local M-cone electrical syncytium (Li and DeVries, 2004) as current flows from the donor cone to neighboring unclamped cones during the voltage step. In this scenario, a slow change in syncytium membrane potential would be followed by fast chem- 

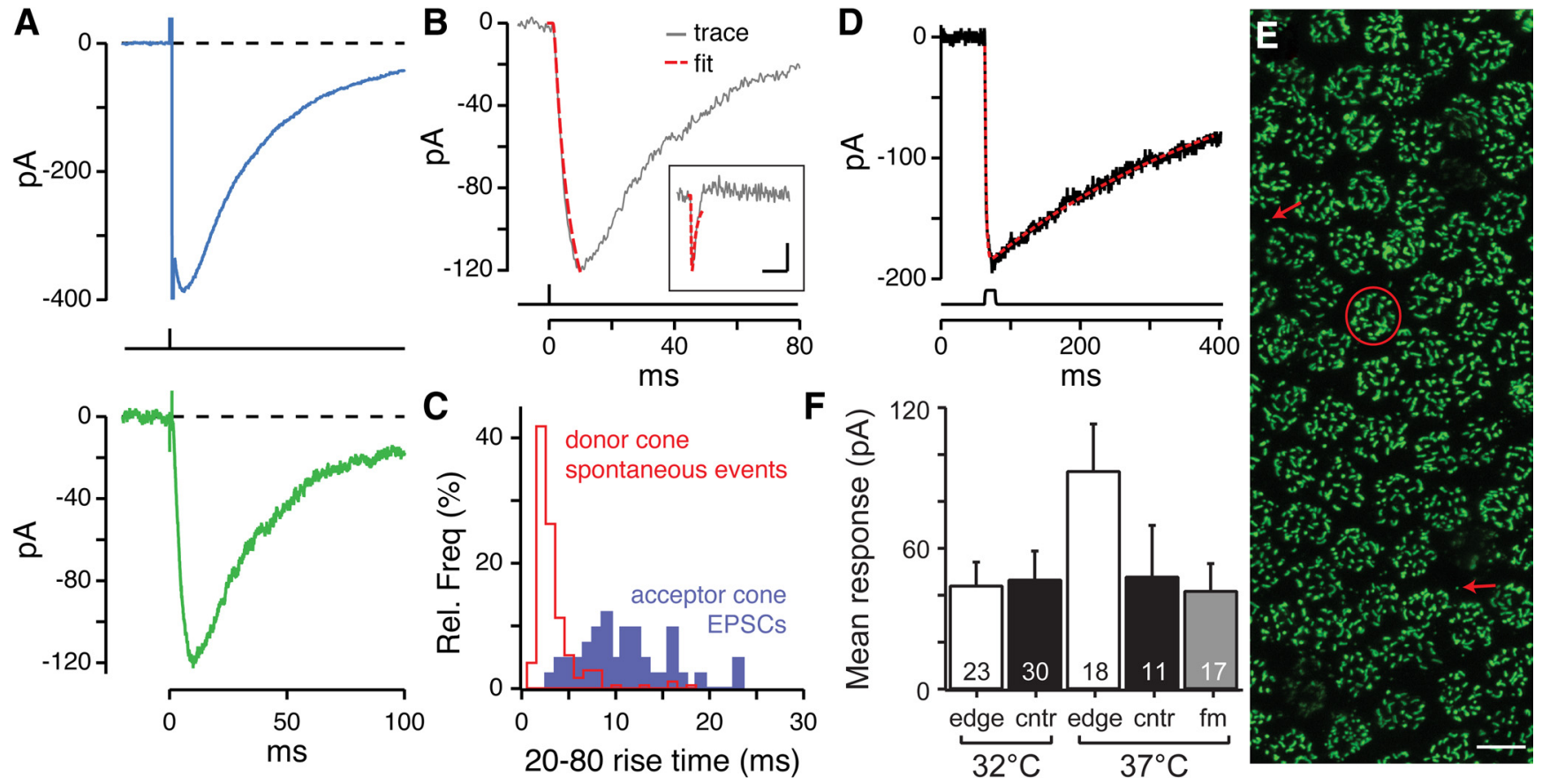

Figure 3. The time course of the acceptor cone response is consistent with cone-cone transmitter diffusion. $A$, Top, A donor S-cone was stepped from -70 to $0 \mathrm{mV}$ for $1 \mathrm{~ms}$. Bottom, Simultaneous membrane current responses in an adjacent M-cone. S- and M-cones are not electrically coupled (Li and DeVries, 2004). $\boldsymbol{B}$, The response of an acceptor M-cone following a $1 \mathrm{~ms}$ depolarization in a donor S-cone. Inset, Derivative of the acceptor cone response based on the assumption that the transporters integrate the local concentration profile of glutamate during impulsive release. The derivative was fitted using an equation for radial diffusion in a hemisphere (red dashed line; see equation, Materials and Methods). The diffusion radius for this pair, as determined by the fit, was $0.93 \mu \mathrm{m}$. The integrated fit is also superimposed on the raw acceptor cone response. Inset, Horizontal scale bar, $20 \mathrm{~ms}$; vertical scale bar, $10 \mathrm{pA}-\mathrm{s}^{-1}$. C, Histogram of $20-80 \%$ rise times of acceptor cone responses following a $1 \mathrm{~ms}$ stimulation of a neighboring donor cone. Plotted for comparison are the rise times of spontaneous events released by and detected in a single cone (Fig. $6 B$, left). $\boldsymbol{D}$, A brief $(10 \mathrm{~ms})$ pulse of glutamate $(1 \mathrm{~mm})$ was rapidly applied to a mechanically isolated cone. The response was fitted with a curve that had an exponential rise time constant, $\tau$, of $1.6 \mathrm{~ms}$ and decay $\tau=397 \mathrm{~ms}$ (red trace). $\boldsymbol{E}$, Flat mount view of cone terminals labeled with an antibody against ribeye (ribbon marker CtBP2; green) showing the photoreceptor mosaic in the ground squirrel. Each cluster of puncta represents one photoreceptor terminal (e.g., red circle). Rods are identified by the small number of ribbons in their terminals (arrows). Scale bar, $5 \mu \mathrm{m}$. $\boldsymbol{F}$, Average acceptor cone response amplitudes (with internal $\mathrm{SCN}^{-}$-containing solution) measured at the edge or center (cntr) of a slice, in flat-mounted (fm) tissue, and at various recording temperatures $\left(32\right.$ or $\left.37^{\circ} \mathrm{C}\right)$. The stimulation protocol was identical to that used in $\boldsymbol{A}$. Numbers at the base of each bar show $n$; error bars indicate SEM.

ical signaling between unclamped cones and an acceptor cone. To rule out a role for the cone syncytium in producing the slow acceptor cone response, we recorded from pairs of short wavelength sensitive (S)- and M-cones (Fig. 3A), which are not electrically coupled (Li and DeVries, 2004). S-cones were identified in retinal flat mounts before recording by their morphological characteristics ( $\mathrm{Li}$ and DeVries, 2004). To measure the time course of the acceptor cone response, we applied a brief (1 ms) $-70-0 \mathrm{mV}$ depolarization to the donor cone. Similar stimuli rapidly empty the cone-releasable pool of vesicles, insofar as a second cone depolarization $70 \mathrm{~ms}$ after the first elicits a relatively small ( $<20 \%$ of the initial peak) response in postsynaptic bipolar cells that express AMPA receptors (receptor recovery: $\tau=18 \mathrm{~ms}$ ) (DeVries, 2000). In addition, we used an $\mathrm{SCN}^{-}$-containing internal solution to increase the size of the cone transporter current [peak auto-feedback current (see below) with $\mathrm{SCN}^{-}$as the main internal anion: $-514.4 \pm 235.3 \mathrm{pA}, n=36$ cells; cf. with $\mathrm{Cl}^{-}\left(\mathrm{E}_{\mathrm{Cl}}=\right.$ $0 \mathrm{mV}$ ) as the internal anion: $-76.2 \pm 16.8 \mathrm{pA}, n=9$ cells]. Figure $3 A$ (top) shows the auto-feedback response in a donor S-cone, which is the response of the S-cone to its own glutamate release. The corresponding acceptor response in the $\mathrm{M}$-cone is shown in Figure $3 A$, bottom. Acceptor responses were found in $\mathrm{S}-\mathrm{M}$ pairs when either the S- or M-cone functioned as a donor, which shows unequivocally that electrical coupling is not required for cone-cone chemical transmission. S- and M-donor cones produced acceptor $\mathrm{M}$-cone responses that differed in several respects. Acceptor responses in S-donor-M-acceptor pairs were smaller than acceptor responses in M-donor-M- acceptor pairs ( $p=0.043$, Wilcoxon rank-sum; mean acceptor response: $-41.4 \pm 47.3 \mathrm{pA}, n=12 \mathrm{~S}-\mathrm{M}$ pairs; mean acceptor response: $-72.6 \pm 68.4 \mathrm{pA}, n=28 \mathrm{M}-\mathrm{M}$ pairs). In addition, the $20-80 \%$ rise time in S-donor-M-acceptor pairs was faster $(p=$ 0.0001, Wilcoxon rank-sum; S-M pairs: $5.7 \pm 1.6 \mathrm{~ms}$; M-M pairs: $10.6 \pm 4.4 \mathrm{~ms})$. Since S-M cone pairs are not electrically coupled while $\mathrm{M}-\mathrm{M}$ pairs are, one possibility is that the larger and slower response in $\mathrm{M}-\mathrm{M}$ pairs is due to glutamate release from neighboring, unclamped $\mathrm{M}$-cones. We cannot rule this possibility out. However, an alternative explanation for the smaller and faster responses in S-donor-M-acceptor pairs (compared with $\mathrm{M}$-donor-M-acceptor pairs) is that the lower ribbon count, smaller ribbons, and more compact pedicle in S-cones (Kolb et al., 1997; Lee et al., 2005) results in S-cones releasing less glutamate and behaving more like a point source of glutamate release, which sharpens the temporal properties of the response.

Given that the acceptor cone responses result from direct cone-to-cone signaling, we next determined whether the time course of the acceptor cone response was consistent with conecone transmitter diffusion. A brief (1 ms) donor S-cone depolarization produced a smoothly rising and decaying response in an acceptor M-cone (Fig. 3B). A frequency histogram of the $20-$ $80 \%$ rise times of the acceptor responses in this and 40 additional $\mathrm{M}-\mathrm{M}$ and S-M pairs is shown in Figure 3C. For comparison, we measured the rise times of the spontaneous events produced when the glutamate contained within a fusing vesicle feeds back to activate transporter currents on the releasing cone (Picaud et al., 1995a). The mean rise times of these feedback events averaged 
$2.9 \pm 2.5 \mathrm{~ms}(n=167$ events from three cells; Fig. $3 C)$. The rise time of the response in the acceptor cone was significantly longer than the rise time of the spontaneous feedback events in the donor cone (10.3 $\pm 4.8 \mathrm{~ms}, n=41, p<0.0001$, Student's $t$ test), consistent with a transmission mechanism that requires cone-cone diffusion.

We also fitted the acceptor cone response using an equation for radial diffusion from a point source in three dimensions (Fig. $3 B$, inset; see Materials and Methods, above, for details), with the assumption that the transporter effectively integrates the local time-dependent glutamate concentration profile following impulse-triggered release. This assumption was supported by the results from rapid perfusion experiments on excised cones (Fig. $3 D)$, which showed that a brief pulse of glutamate $(<10 \mathrm{~ms}$ in duration), similar in duration to that occurring after brief cone depolarization, produced a rapidly rising $(\tau=1.6 \mathrm{~ms})$ and slowly decaying $(\tau=\sim 400 \mathrm{~ms})$ transporter current $(n=2)$. The effective diffusion radius, obtained from fits like those shown in Figure $3 B$, was $1.56 \pm 0.40 \mu \mathrm{m}(n=22)$. For comparison, cones in the superior retina of the ground squirrel form a quasi-crystalline array with a nearest-neighbor center-to-center spacing of $5.14 \pm$ $0.67 \mu \mathrm{m}(n=298$ cones from three retinas; Fig. $3 E)$. There is no evidence for telodendrial contacts between ground squirrel cone terminals, hence the results are consistent with the idea that glutamate diffuses from release sites located near the edge of a donor cone to transporter detectors near the periphery of the acceptor cone. It follows that cone-cone chemical signaling was only observed in adjacent cone pairs; no acceptor cone currents were seen in 18 cone pairs that were separated by at least a single intervening cone.

Crosstalk might be artificially enhanced if glutamate reuptake is impaired in the slice preparation. Muller cell transport could be interrupted by injury during slicing, and transport in both the cone and Muller cells might be reduced at the subphysiological temperatures normally used for recording $\left(32^{\circ} \mathrm{C}\right)$. To address these concerns, Figure $3 F$ shows results obtained from conecone pairs under a variety of conditions: either at the edge or in the middle of a $100 \mu \mathrm{m}$ thick slice, or in the flat-mounted retina; and, either at 32 or $37^{\circ} \mathrm{C}$. A $100 \mu \mathrm{m}$ slice contains $\sim 15$ cones in cross section, so the edge was taken to be within four cones from the cut surface. The size of the transporter current in acceptor cones does not significantly differ under any condition (one-way ANOVA, $p=0.096$ ). The results suggest that cone-cone crosstalk is not an artifact of impaired glutamate uptake by Muller cells.

One possibility is that cone-cone spillover is indirect and caused by Muller cells that respond to the transmitter released by a donor cone and then rebroadcast the signal by releasing glutamate onto nearby acceptor cones (Parpura et al., 1994; Pasti et al., 1997; but see Agulhon et al., 2010). We tested this hypothesis by measuring the reciprocal signaling between a cone and a Muller cell during paired voltage-clamp recordings. We focused on rapid channel- or transporter-mediated responses as opposed to slow second messenger-mediated responses (Rillich et al., 2009) since, as shown below, Muller cells would need to rebroadcast the cone signal with minimal delay (e.g., $<1-2 \mathrm{~ms}$ ). A brief cone depolarization produced a $5-15 \mathrm{pA}$ response in a postsynaptic Muller cell that was completely blocked by TBOA $(280 \mu \mathrm{M})$, and thus entirely due to the activation of a glutamate transporter (the standard saline contains CNQX; $n=5$ pairs; two cones were recorded in the whole-cell configuration, whereas three were depolarized in the loose seal configuration). The Muller cell current had a rise time of $4.8 \pm 2.5 \mathrm{~ms}$, which is approximately half that obtained for chemical transmission between pairs of M-cones (Fig. $3 B, C$ ). A similar temporal response would be expected in the event of reverse signaling between a Muller cell and an acceptor cone, hence the delay imposed by the Muller cell should be short. Muller cell depolarization to $+30 \mathrm{mV}$ failed to elicit a cone response in the two pairs in which cones were recorded in the whole-cell configuration. The results do not support a rapid, rebroadcasting role for Muller cells: cone transmitter release evokes a glutamate transporter current in Muller cells, but Muller cell depolarization does not produce a reciprocal signal in cones. Nonetheless, we cannot completely exclude the occurrence of a voltage independent, $\mathrm{Ca}^{2+}$-mediated glutamate release from Muller cells either following $\mathrm{Ca}^{2+}$ influx at the transporter or through a transmitter-gated $\mathrm{Ca}^{2+}$ conductance that is too small to be consistently observed in voltage clamp.

\section{Cone-cone crosstalk under physiological conditions}

We next wanted to determine whether crosstalk occurs during the physiological stimulus - light. The idea was to duplicate, as closely as possible, the conditions of the paired voltage-clamp experiments. Thus, we recorded from an S-cone in a flatmounted preparation and maintained its membrane voltage at $-70 \mathrm{mV}$ to silence glutamate release. The S-cone acted as the acceptor cone. We then stimulated a $250 \mu \mathrm{m}$ diameter field, centered on the S-cone, with $574 \mathrm{~nm}$ light. M-cones are three orders of magnitude more sensitive to $574 \mathrm{~nm}$ light than S-cones (Kraft, 1988). During the $574 \mathrm{~nm}$ light step, M-cones should hyperpolarize and cease transmitter release. At light-off, the M-cones will depolarize, releasing transmitter in a bolus followed by a steady rate. During the release at light-off, the $\mathrm{M}$-cones act as donor cones. Using an S-cone, rather than an M-cone, as the acceptor cone eliminates the potential for current spread through gapjunction channels (Li and DeVries, 2004). To monitor the size of the light response, we simultaneously recorded from a nearby M-cone in current clamp.

Crosstalk during a light stimulus was first examined with $\mathrm{SCN}^{-}$as the main intracellular anion (Fig. 4). Under control conditions, a $500 \mathrm{~ms}$ step of light produced a $\sim 12 \mathrm{mV}$ membrane hyperpolarization in a donor M-cone (Fig. $4 \mathrm{~A}$, black and green traces), which was followed by a $10-15 \mathrm{mV}$ transient depolarization at light-off. The glutamate transporter blocker TBOA had three effects on the time course of the light response. TBOA hyperpolarized the $\mathrm{M}$-cone in the dark; it revealed a decay to a plateau level during the light pulse and it blocked a transient depolarization at light-off (Fig. 4A, top, red trace). All of the effects of TBOA on the $\mathrm{M}$-cone light response can be viewed as resulting from glutamate auto-feedback. First, in the dark, there is a tonic activation of the transporter anion current by glutamate, and possibly a nonspecific transporter leak current (Otis and Kavanaugh, 2000), both of which, when blocked by TBOA, lead to a membrane hyperpolarization when the intracellular solution contains $\mathrm{SCN}^{-}$. Second, during the light pulse, glutamate release stops and cleft concentrations decrease. The resulting decrease in inward current leads to a steady hyperpolarization under control conditions; blocking the hyperpolarization with TBOA reveals a depolarizing voltage plateau (Bader et al., 1982; Barnes and Hille, 1989; Barrow and $\mathrm{Wu}, 2009$ ). Finally, a transient depolarization at light-off is due to a bolus of transmitter release (Jackman et al., 2009), which feeds back on the releasing cone to activate the transporter current; TBOA completely blocks this component.

The response of the central S-cone should reflect the local changes in glutamate concentration due to diffusion from neighboring $\mathrm{M}$-cones during a light response. Cones do not release transmitter at a holding potential of $-70 \mathrm{mV}$, ruling out autofeedback as the mechanism for the responses in the S-cone. The 


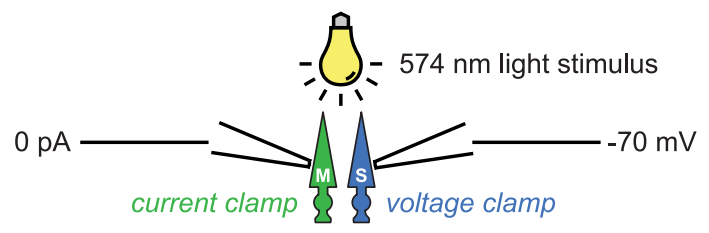

A
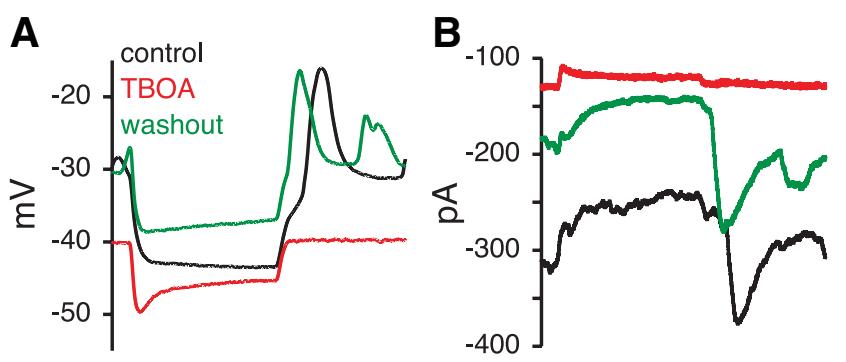

(baseline subtracted)
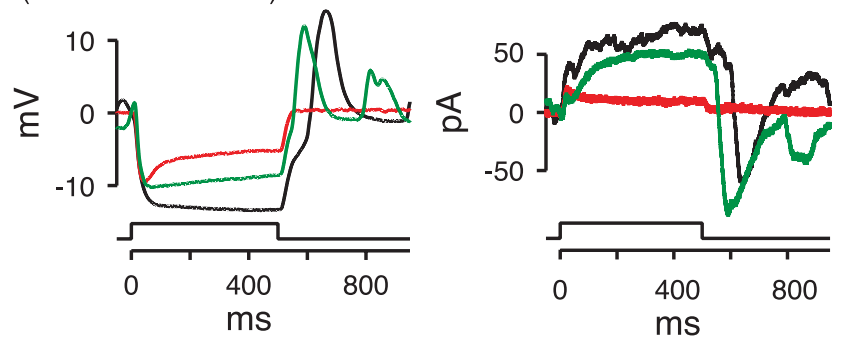

Figure 4. Cone- cone chemical transmission occurs during light responses. Top, Diagram of experiment. A $574 \mathrm{~nm}$ light flash was used to stimulate M-cones. M-cone voltage responses were recorded in current clamp. The current responses of a nearby $S$-cone were simultaneously measured at a steady holding potential of $-70 \mathrm{mV}$ in voltage clamp. $S$ - and $\mathrm{M}$-cone responses were recorded with $\mathrm{SCN}^{-}$as the main intracellular anion. $\boldsymbol{A}, \boldsymbol{B}, \mathrm{M}$-cone response $(\boldsymbol{A})$ and simultaneous $S$-cone response $(\boldsymbol{B})$ to $574 \mathrm{~nm}$ light flash before (black trace), during (red), and after (green) TBOA (280 $\mu \mathrm{m})$ application. Top, Actual voltage or current traces; bottom, baseline-subtracted traces.

recorded S-cone had a maintained inward current in the dark (Fig. $4 B$, top, black and green traces), a slow suppression of the inward current during the light stimulus, and a transient increase in inward current at light-off. TBOA (Fig. $4 B$, top, red trace) blocked the steady inward current in the dark, the slowly increasing outward current during the light step, and the transient inward current at light-off. The remaining small outward current response in the S-cone during TBOA application probably resulted from a weak activation of S-cone opsin by the $574 \mathrm{~nm}$ light (Kraft, 1988). Based on our description of the M-cone response, these effects are expected if: there is a tonic flow of glutamate in the dark from neighboring $\mathrm{M}$-cones to transporter sites on the $\mathrm{S}$-cone, the glutamate flow is diminished when $\mathrm{M}$-cones hyperpolarize in the light and cease transmitter release, and the glutamate flow is enhanced by a bolus of release from $\mathrm{M}$-cones at light-off. Similar results were obtained in five experiments with an outward current in the S-cone during the light pulse of $30.8 \pm$ 17.2 $\mathrm{pA}$ and an inward transient at light-off that peaked at $109.7 \pm 26.6 \mathrm{pA}$ (the small residual light response, seen during drug application, was subtracted for these measurements). These results, obtained in the flat-mounted retina at recording temperatures of $37^{\circ} \mathrm{C}$, show that the flow of glutamate between cones is regulated by light.

The magnitude and polarity of cone-cone crosstalk depends on the reversal potential for the transporter current, which is predominantly carried by $\mathrm{Cl}^{-}$in the intact cone. To determine the reversal potential, we applied voltage ramps in the absence or presence of glutamate while recording from cones using the gramicidin perforated-patch technique (Fig. $5 A, B$ ), which preserves the intracellular $\mathrm{Cl}^{-}$concentration. The difference current from a single experiment (Fig. $5 A$, black trace) crossed the abscissa at $-42.7 \mathrm{mV}$. The membrane at the tip of the pipette was then ruptured, allowing a pipette solution that contained the same $\mathrm{Cl}^{-}$concentration as the bath to diffuse into the cell. After rupture, the glutamate-gated current reversed at $+11.4 \mathrm{mV}$ (Fig. $5 A$, brown trace). This exemplar experiment was chosen as it was the most stable and repeatable of the four experiments that included a rupture current. In a total of 10 experiments (Fig. 5B), the glutamate-gated current during perforated-patch recording reversed at $-31.1 \pm 3.5 \mathrm{mV}$ (mean $\pm \mathrm{SEM})$, whereas the wholecell recording with $\mathrm{E}_{\mathrm{Cl}}=\sim 0 \mathrm{mV}(n=4)$ reversed at $+18.2 \pm$ $14.6 \mathrm{mV}$ (mean $\pm \mathrm{SEM}$ ). The quality of the perforated-patch recordings was verified in two ways: First, fluorescent tracer in the pipette solution was excluded from the cone before membrane rupture (verified in $n=7$ cones); second, the measured transporter reversal potential was stable from the start of perforated recording for up to $13 \mathrm{~min}$ thereafter $(n=10)$. Our results suggest that transporter activation elicits an outward anion current and thus causes cones to depolarize at the cone dark resting potential of $\sim-50 \mathrm{mV}$. Several groups (Sarantis et al., 1988; Tachibana and Kaneko, 1988; Thoreson and Bryson, 2004; but see Picaud et al., 1995a) have observed a similarly depolarizing transporter reversal potential in salamander and turtle cones.

To more closely mimic physiological conditions, we switched to an intracellular solution that had $\mathrm{a} \mathrm{Cl}^{-}$reversal potential of $-30 \mathrm{mV}$ and then measured the response to light as described above. In cell pair experiments, exchanging $\mathrm{Cl}^{-}$for $\mathrm{SCN}^{-}$reduced the size of the transporter current by sixfold, and shifting the $\mathrm{Cl}^{-}$reversal potential from 0 to $-30 \mathrm{mV}$ further reduced the size of the transporter current by 1.5 -fold $[n=40$ cells recorded with $\mathrm{SCN}^{-} ; n=9$ cells with $\mathrm{Cl}^{-}\left(E_{\text {rev }}=0 \mathrm{mV}\right) ; n=47$ cells with $\left.\mathrm{Cl}^{-}\left(E_{\mathrm{rev}}=-30 \mathrm{mV}\right)\right]$. During the experiment, a currentclamped M-cone (Fig. 5C) responded to a light step with a 13-15 $\mathrm{mV}$ hyperpolarization. The depolarization at light-off rose abruptly, but ended in a slight undershoot, which characteristically occurs in cones following bright flashes (Nikonov et al., 2008). Figure $5 D$ shows the responses of a nearby S-cone recorded at a series of holding potentials between -83 and $-8 \mathrm{mV}$. At a holding potential of $-68 \mathrm{mV}$ (liquid junction potential corrected), the light step suppressed a steady $4 \mathrm{pA}$ current and produced a $1 \mathrm{pA}$ inward current at offset. The amplitude of the suppressed current increased at a holding potential of $-83 \mathrm{mV}$ and reversed in the interval between -38 and $8 \mathrm{mV}$. Following recording, the identity of the $\mathrm{S}$-cone was verified by using an antibody that recognized S-opsin (Fig. $5 E$ ). In a total of 11 cone recordings performed with physiological intracellular $\mathrm{Cl}^{-}\left(E_{\mathrm{rev}}=\right.$ $-30 \mathrm{mV}$ ) solution (Fig. $5 F$ ), the amplitude of the outward current during the light step was $3.31 \pm 1.91 \mathrm{pA}($ mean $\pm \mathrm{SD})$ at a holding potential of $-68 \mathrm{mV}$. At the same holding potential, the peak inward current at light-off was $-1.59 \pm 0.68 \mathrm{pA}$. Two additional S-cones had responses consistent with an absence of cone-cone signaling. The measured conductance of the S-cones was $2.35 \pm 0.36 \mathrm{nS}$ ( $n=4$ cones), thus the $4.9 \mathrm{pA}$ cone current change during and after the light step should produce a response that ranges over $\sim 2 \mathrm{mV}$ (compared with a $10-15 \mathrm{mV}$ peak hyperpolarization during a typical monophasic cone light response). For comparison, if S- and M-cones were electrically coupled to the same extent as M-cones $\left(g_{\mathrm{gj}}=200 \mathrm{pS}\right)(\mathrm{Li}$ and DeVries, 2004), using the same type of calculation, the light responses of five to six neighboring cones would inject $12-14 \mathrm{pA}$ into the central cone, producing a $5-6 \mathrm{mV}$ response. The re- 


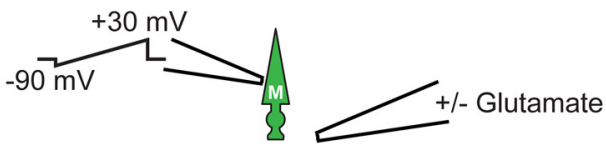

A
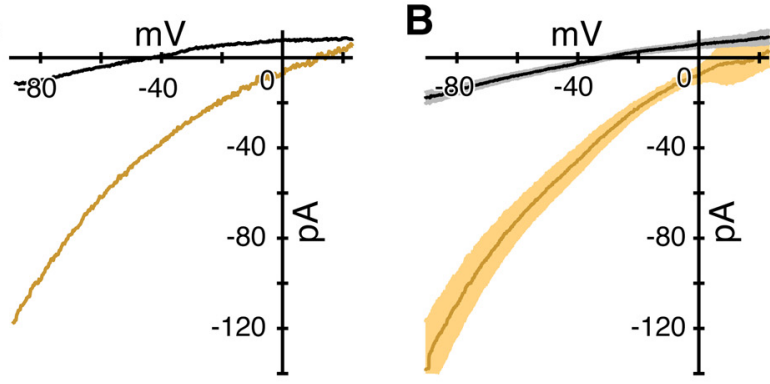

Key: - Gramicidin D; - Whole-cell
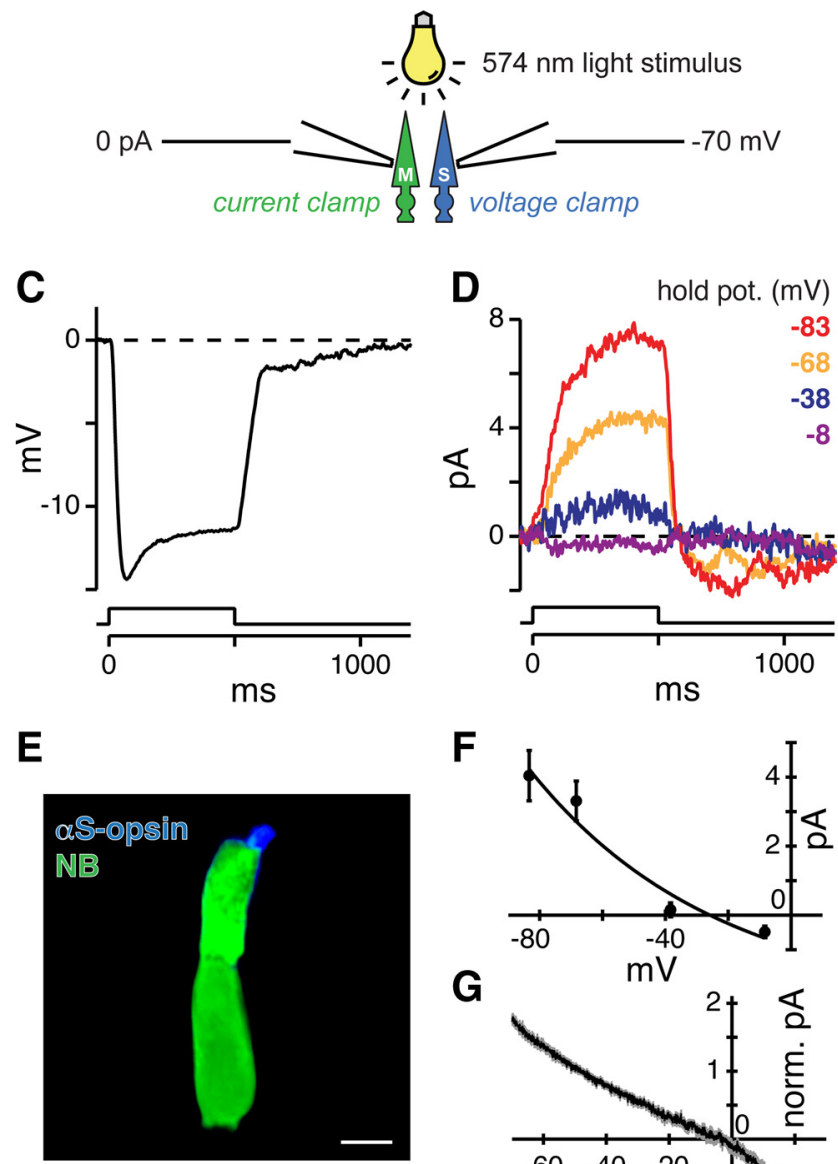

$\mathbf{F}$

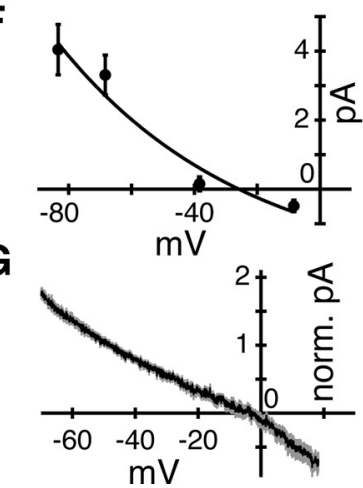

Figure 5. Chemical transmission during light responses at physiological intracellular $\mathrm{Cl}^{-}$ concentrations. $\boldsymbol{A}, \boldsymbol{B}$, The reversal potential of the cone glutamate transporter. Experimental paradigm shown above. The pipette solution contained the perforating agent gramicidin $\mathrm{D}$. Membrane voltage was ramped from -90 to $+30 \mathrm{mV}$ in the absence and presence of $1 \mathrm{~mm}$ glutamate. Difference currents are shown. $\boldsymbol{A}$, The glutamate-gated current of an individual cone before (black trace) and after (gold trace) the membrane occluding the pipette tip was ruptured. $B$, Average results for 10 cones (perforated, black trace). Four of the cones were successfully ruptured following the initial measurements (gold trace). Mean response (solid line) and SEM (shaded region). C-G, Cone-cone chemical transmission during light responses measured with an intracellular $\mathrm{Cl}^{-}$concentration calculated to provide a reversal potential of $-30 \mathrm{mV}$. Experimental paradigm shown above $C$ : except for internal solution changes, the protocol was identical to that of Figure 4. C, D, M-cone light response in current clamp $(\boldsymbol{C})$ and simultaneous $S$-cone response in voltage clamp (D). The $\mathrm{S}$-cone was maintained at four membrane voltages sponses in the S-cone during the light step reversed at $\sim-26 \mathrm{mV}$ $(n=11$ cells; Fig. $5 F)$. Since the $\mathrm{S}$-cone response to the M-cone stimulus reversed at a more positive value than predicted (i.e., $-30 \mathrm{mV}$ ), we infer that the transporter response is contaminated by a small, direct light response. The reversal potential of the light-gated conductance alone was $-3.7 \pm 2.2 \mathrm{mV}(n=8$ cones; Fig. $5 G$ ), supporting this conclusion. Thus, glutamate readily diffuses between cones during a light response, but under physiological conditions, the maximal effect should be to change cone membrane voltage by $\sim 2 \mathrm{mV}$, or $13-20 \%$ of the light response amplitude. The voltage change is limited by the relatively negative reversal potential of the transporter $\mathrm{Cl}^{-}$current.

\section{Released glutamate saturates transporters in donor cones}

The glutamate released at the mouse rod terminal is completely sequestered by transporters located at the terminal (Hasegawa et al., 2006). Our results on cone-cone signaling suggest that glutamate is not completely sequestered by transporters on the releasing cone. One way that this could happen is if cone transporter glutamate binding sites become saturated during transient release. We used two approaches to address whether the amount of transmitter released by a cone during a short interval (e.g., $10 \mathrm{~ms}$ ) can exceed the transporter binding capacity. Both approaches made use of auto-feedback: the observation that glutamate released by an individual cone activates transporters on the same cone (Picaud et al., 1995a). In the first approach, we calculated the quantal content of a transporter EPSC by comparing maximal and miniature EPSC amplitudes. We reasoned that if transporters are saturated during a maximal EPSC, than the effective quantal content of the maximal EPSC should be less than the number of docked vesicles as determined by electron microscopic reconstruction $[\sim 20$ per ribbon or 400 per terminal in the salamander (Jackman et al., 2009); 600-700 docking sites at 20-40 ribbons in the cat and primate (Sterling and Matthews, 2005)]. In the second approach, we simultaneously recorded from a cone and a postsynaptic Off bipolar cell and compared the size of auto-feedback on the cone, which is mediated by glutamate transporters, to the size of the postsynaptic EPSC in the bipolar cell, which is mediated by ionotropic glutamate receptors. Glutamate transporters are inferred to saturate if the peak amplitude of the cone transporter response plateaus before that of the postsynaptic bipolar cell response.

We estimated the size of the transporter unitary event from a mean variance analysis of evoked events at threshold. Figure $6 \mathrm{~A}$ (left) shows the response of a single $\mathrm{M}$-cone to a series of brief, low-amplitude $(-70--40 \mathrm{mV})$ membrane depolarizations. Event amplitudes varied between 0 (failures) and $150 \mathrm{pA}$. The relatively large event amplitudes and long durations suggest that the underlying variability is caused chiefly by stimulus-tostimulus variations in the number of vesicle fusions rather than by single-channel fluctuations. The peak variance divided by the peak mean current (Fig. 6A, right) provides an estimate of the unitary peak current, which was $-14.7 \mathrm{pA}$ for the cell in Figure $6 A$ (average $-12.8 \pm 5.2 \mathrm{pA} ; n=5$ cells). To confirm this number, we measured the amplitudes of spontaneously occurring

$\leftarrow$

during light stimulation (shown at right). $E$, S-cones were filled with Neurobiotin (NB) during recording and subsequently identified by labeling with an S-opsin antibody. C-E are from the same recording. Scale bar, $5 \mu \mathrm{m}$. $\boldsymbol{F}$, Plot of peak $S$-cone response in light versus membrane voltage; $n=11$ cells, mean \pm SEM. Data points were fitted with an exponential curve. The response reversed at $-26 \mathrm{mV}$. G, The S-cone light transduction current was measured by applying a voltage ramp before and during a bright $468 \mathrm{~nm}$ light flash. The transduction current reversed at $-3.7 \mathrm{mV}$. Average ( \pm SEM) difference traces ( $n=8$ cones). 


\section{A Evoked EPSCs}

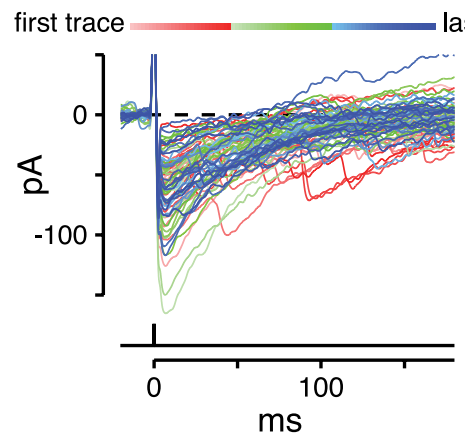
ast trace
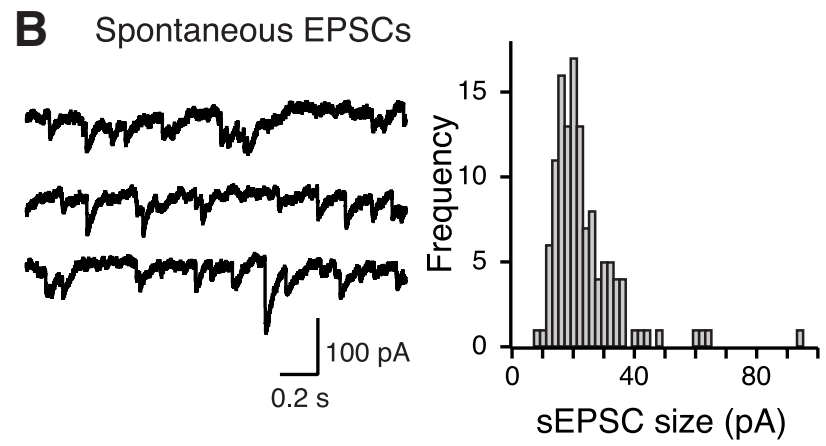

\section{Maximal EPSCs}
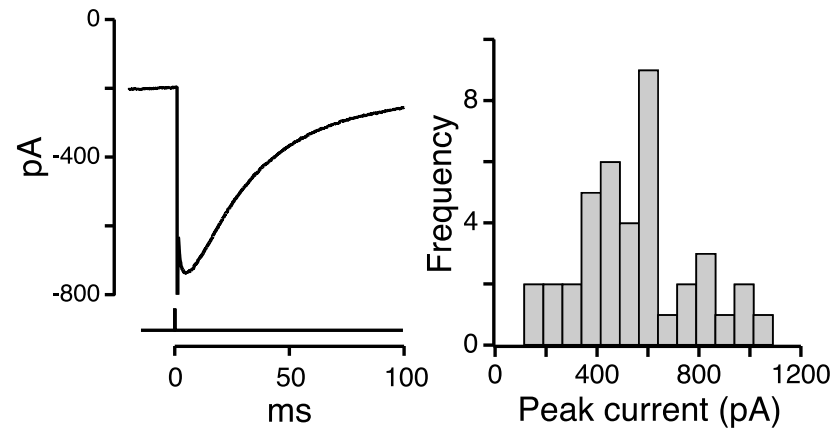

Figure 6. Evidence that transporters saturate during a maximal EPSC. The pipette solution contained $\mathrm{SCN}^{-}$to increase the size of the transporter current. $A$, Left, Submaximal EPSCS evoked by a train of $1 \mathrm{~ms}$ depolarizing pulses from -70 to $-40 \mathrm{mV}$. Traces are color-coded according to their order of acquisition to illustrate response stability. Right, Plots of response mean and variance, calculated from the data on the left. $\boldsymbol{B}$, Left, Spontaneous transporter current events (sEPSCs) in an M-cone held at $-70 \mathrm{mV}$. Right, Amplitude histogram of spontaneous transporter current events amplitudes obtained from a total of 20 consecutive $2 \mathrm{~s}$ traces in a single M-cone. C, Left, Maximal M-cone EPSC elicited by depolarizing the cone from -70 to $0 \mathrm{mV}$. Right, Histogram of peak transporter current for $36 \mathrm{M}$ - and S-cones.

events. Figure $6 B$ (left) shows a series of traces from a cone whose voltage was maintained at $-70 \mathrm{mV}$. The amplitudes of the spontaneous transporter events were measured in the traces shown plus 17 consecutive traces. A histogram of peak event amplitudes (Fig. $6 B$, right) had a median amplitude of -19.6 pA. Similar results were obtained from a total of five cones (median event amplitude averaged $-23.1 \pm 3.9 \mathrm{pA}$ ). Finally, maximal EPSCs (Fig. 6C, left) were obtained by briefly depolarizing a cone to a voltage $>0 \mathrm{mV}$, which should exhaust the entire releasable pool of vesicles (DeVries, 2000). An amplitude histogram of maximal EPSCs (Fig. 6C, right) indicated a peak transporter current of $-514 \pm 235 \mathrm{pA}(n=36$ cells $)$. Given the unitary event amplitude of $15-20 \mathrm{pA}$, we calculate that $25-35$ vesicles would sum to create a maximal transporter EPSC. This number of vesicles is consid-
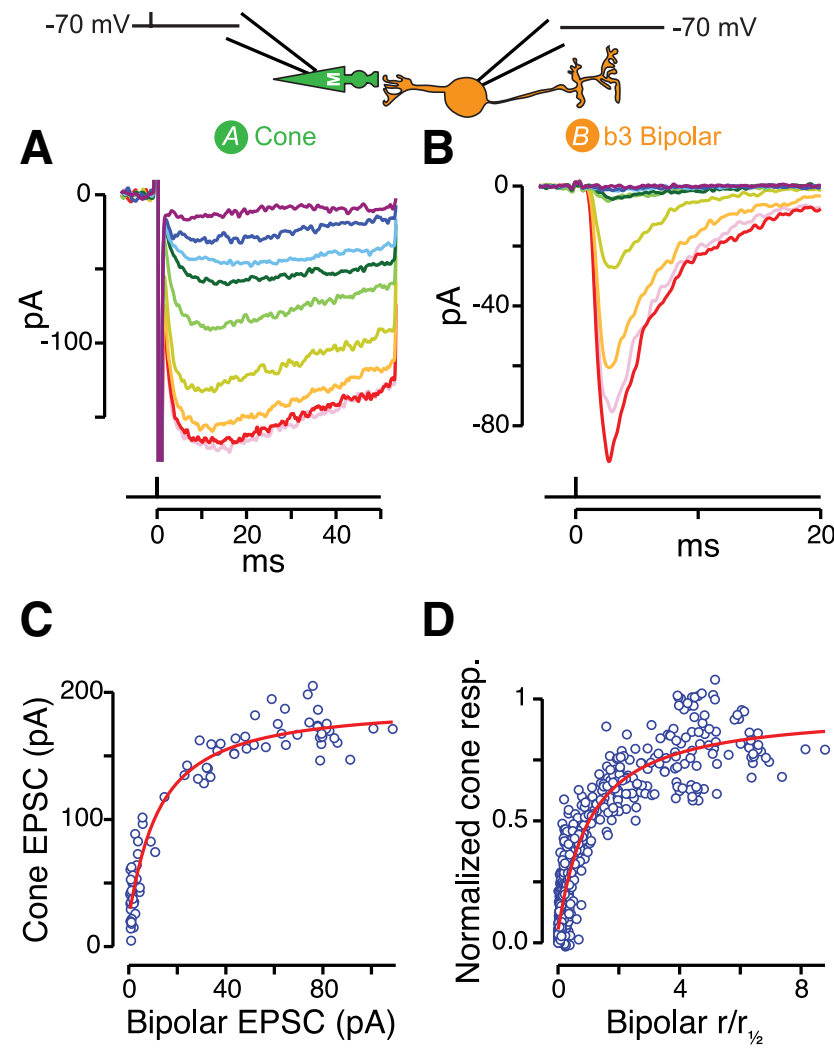

D

E
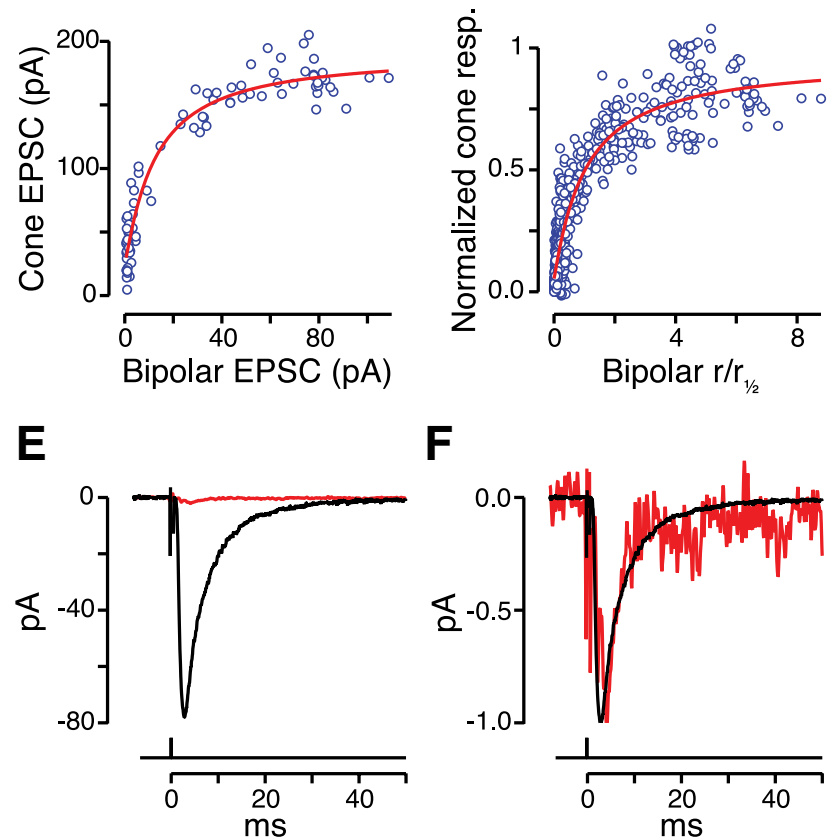

Figure 7. Cone transporters saturate before postsynaptic bipolar cell glutamate receptors The experiment configuration is shown above. The cone received a train of depolarizing pulses (1 ms duration, 1 s interval). Differences in stimulation amplitude and run-down of cone glutamate release produced variable responses in the cone and bipolar cell. $\boldsymbol{A}$, Cone transporter currents. Each trace is an average of five consecutive responses obtained at intervals of 10 pulses (overlapping traces have been omitted for clarity). Transporter currents were amplified by including $\mathrm{SCN}^{-}$in the pipette solution. $\boldsymbol{B}$, Simultaneous EPSCS in a b3 bipolar cell. Matching colors in $\boldsymbol{A}$ and $\boldsymbol{B}$ indicate corresponding presynaptic and postsynaptic currents. Traces in $\boldsymbol{A}$ and $\boldsymbol{B}$ are leak-subtracted. $\boldsymbol{C}$, Plot of peak cone transporter current amplitude versus peak bipolar cell EPSC amplitude for all the responses in the pair shown in $\boldsymbol{A}$ and $\boldsymbol{B}$. The data points were fitted using a Hill equation. $\boldsymbol{D}$, Grouped responses. Data from individual plots was fitted with a Hill equation and cone responses were normalized by the extrapolated maximum value. Bipolar cell responses (r) were normalized to their half-maximal amplitude. $\boldsymbol{E}$, Bipolar cell response to a -70 to $-10 \mathrm{mV}$ step obtained near the start of the experiment (black trace, corresponds to the maximal responses in $\boldsymbol{B}$ ). Response of the bipolar cell to the same amplitude cone step recorded $140 \mathrm{~s}$ after the start of the experiment, following run down (red trace, obtained $45 \mathrm{~s}$ after the last trace plotted in $\boldsymbol{B}$ ). $\boldsymbol{F}$, Bipolar cell EPSC responses from $\boldsymbol{E}$ normalized and superimposed. The time courses are similar.

erably less than the $600-700$ vesicles that are predicted to be docked on ribbons at the cone terminal membrane in mammals (Sterling and Matthews, 2005). In addition, by comparing the unitary event amplitude during feedback (15-20 pA) to the amplitude of the acceptor cone response during a maximal donor 
A

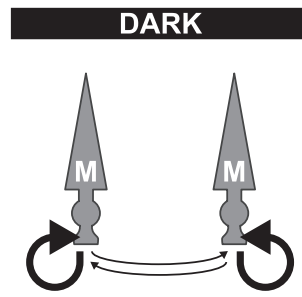

B

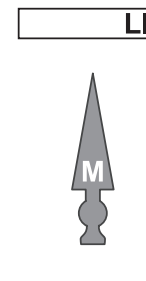

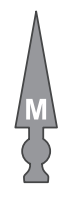

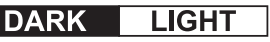

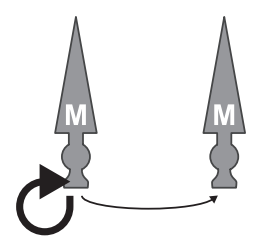

Figure 8. Properties of cone-cone spillover. $A$, Volume transmission will have a minimal effect on a population of cones in the dark due to the proximity of glutamate release sites and transporters at the base of each cone. $\boldsymbol{B}$, In uniform light, glutamate release is suppressed and thus spillover is precluded. $\boldsymbol{C}$, At light- dark borders, the glutamate released by the cones in the dark will spillover and activate transporters on cones in the light (i.e., whose release is suppressed). Spillover will provide a depolarizing input that partially counteracts the hyperpolarizing effect of light and which primes the cone to depolarize at light-off.

\section{Discussion}

The ability to resolve spatial detail depends on the ability of cones within a tightly packed array to independently encode incident light intensity, and to separately signal to postsynaptic bipolar cells. Cone and Muller cell reuptake mechanisms are thought to restrict glutamate spread between terminals. Instead, we found that the glutamate released by depolarizing one cone can be detected in neighboring cones. We consider two extremes: first, that crosstalk plays a purely constructive role in visual signal processing; second, that crosstalk is a deleterious but minicone stimulus ( $62.9 \pm 63.7 \mathrm{pA}, n=42$, also obtained with $\mathrm{SCN}^{-}$ as the intracellular anion), we can crudely estimate that an acceptor cone receives the equivalent glutamate content of three to four vesicles.

A second way to demonstrate transporter saturation is to compare the amplitude of the transporter EPSC with that of an EPSC measured simultaneously in a postsynaptic Off bipolar cell during a series of cone depolarizations. In a typical experiment, a cone was briefly (1 ms) stepped to a depolarized voltage while the responses in both the presynaptic cone (Fig. 7A) and postsynaptic bipolar cell (Fig. 7B) were measured. The amplitude of the bipolar cell (in this case, a b3-type bipolar cell) EPSC varied both due to changes in cone pulse amplitude and run-down of cone release over time. A plot of cone versus bipolar cell EPSC amplitude (Fig. 7C) shows a saturating profile: the bipolar cell response increased over a range in which the cone EPSC amplitude remained relatively constant. The data points were fitted with a Hill equation that had a half-maximal value of $12.38 \mathrm{pA}$ and a coefficient of 1.11. A similar saturating relationship was obtained in nine pairs whose normalized responses are plotted in Figure $7 D$.

Strong cone depolarization might, via electrical coupling, elicit transmitter release from neighboring cones onto the recorded postsynaptic bipolar cell (Li et al., 2010). In this case, bipolar cell EPSC responses might continue to increase after the cone transporter currents plateaued, falsely providing a saturating relationship. This scenario was unlikely for two reasons. First, cone release runs down after several minutes of recording in the whole-cell configuration. After run down, a depolarizing cone pulse that was either the same amplitude or larger than earlier pulses that evoked a maximal bipolar cell EPSC failed to produce a bipolar cell response $(n=9$; Fig. $7 E)$. Responses would not completely run down if a component were mediated by intact neighboring cones. Second, unclamped neighboring cones depolarize with a time constant of $4.0 \mathrm{~ms}$ following current injection through gap junctions, which produces a delayed, secondary response in postsynaptic bipolar cells (Li et al., 2010). However, in all but one case ( $n=8$ of 9 ), the shape of the bipolar cell EPSC did not vary with amplitude (Fig. $7 B, F$ ). In one pair, there was a small lengthening of the bipolar cell EPSC decay time during the cone depolarization that produced the four largest EPSCs.

Transporters and bipolar cell glutamate receptors (b3/b7) are both located at the base of the cone terminal; therefore, saturation in the transporter is most likely due to the higher $\mathrm{EC}_{50}$ of the glutamate receptors $(\sim 350 \mu \mathrm{M})$ (DeVries et al., 2006) relative to that of glutamate transporters (10-20 $\mu \mathrm{M}$ ) (Barbour et al., 1991; Vandenberg et al., 1998). Thus, the results are consistent with the idea that the saturation of cone transporters during a strong depolarization allows excess transmitter to spill out of the cleft. mized consequence of cone signaling.

Cone-cone crosstalk may play a constructive role in signaling. Cones rest at $\sim-45 \mathrm{mV}$ in the dark and continuously release glutamate. In the salamander, glutamate feeds back onto the releasing cone to activate a transporter anion conductance. It would make sense for this feedback to be negative (i.e., to have a reversal potential lower than $-45 \mathrm{mV}$ ), insofar as a membrane hyperpolarization would tend to balance the depolarization produced by synaptic $\mathrm{Ca}^{2+}$ channels and maintain those channels near the bottom of their activation curve. Indeed, a negative transporter reversal potential was inferred by observing the effects of glutamate on cone intracellular $\mathrm{Ca}^{2+}$ levels (Picaud et al., 1995a). A negative reversal potential and feedback is also found in On bipolar cell terminals, which depolarize to light (Palmer et al., 2003; Veruki et al., 2006). However, the present and three previous studies report a relatively positive cone transporter current reversal potential of $-45--30 \mathrm{mV}$ (Sarantis et al., 1988; Tachithan a role in stabilizing the dark resting potential, positive feedback at the cone terminal could quicken the repolarization at light-off (Rowan et al., 2010), which would speed-up signaling in the Off pathway.

Extending the concept of positive feedback to glutamate spillover, our results suggest that cones are enmeshed in a spatially distributed positive feedback network. The properties of this feedback are potentially complex (Fig. 8): glutamate will flow between cones when the population is uniformly depolarized in the dark, but cone-cone transmission will have little effect insofar as cones are most responsive to their own released glutamate (Fig. $8 \mathrm{~A}$ ). Cone-cone transmission will also be inoperative when a population of cones is hyperpolarized by light, since no glutamate is released (Fig. $8 B$ ). Instead, cone-cone transmission will have an effect when one cone is depolarized while its neighbor is hyperpolarized, which occurs at dark-light borders (Fig. 8C). In this case, the illuminated cone is predicted to receive a depolarizing input from its neighbor, which might prime it to depolarize in the likely event that the dark region moves. Thus, we anticipate that a moving dark bar on a light background will produce a faster cone voltage response on its leading edge (i.e., a light-to-dark transition) than on its trailing edge (a dark-to-light transition). Alternatively, crosstalk in the presence of a moving bar may compensate for the relatively slow decay of the cone photoresponse at light-off compared with its rise at light-on (Kraft, 1988). Predictive coding is a common feature of retinal responses (Berry et al., 1999; Hosoya et al., 2005).

While mammalian cones lack an ultrastructural substrate for cone-cone chemical transmission, lower vertebrate cones make bana and Kaneko, 1988; Thoreson and Bryson, 2004). Rather 
discrete contacts. Photoreceptor terminals in turtles, salamanders, and fish extend telodendria that contact nearby photoreceptors either at their base or within invaginations (Lasansky, 1973; Scholes, 1975; Mariani and Lasansky, 1984; Kolb and Jones, 1985). Salamander and turtle cone terminals contain a transporter $\mathrm{Cl}^{-}$conductance (Sarantis et al., 1988; Tachibana and Kaneko, 1988; Picaud et al., 1995b) that, if located on telodedria, could mediate depolarizing crosstalk (Sarantis et al., 1988; Tachibana and Kaneko, 1988; Thoreson and Bryson, 2004). Anatomical studies show indiscriminate synaptic contacts among turtle red and green cones (Kolb and Jones, 1985), and wavelengths that excite green cones affect the responses of red cones (Normann et al., 1984; Normann et al., 1985). Thus, there is a precedent in lower vertebrates for the cone-cone transmission observed in the ground squirrel. In turn, cone-cone chemical transmission in the ground squirrel may serve as a precedent for transmission in the primate foveal region, which is also cone-rich.

What if glutamate spillover is a deleterious but unavoidable consequence of maximizing the release rate at cone synapses? In this view, the deleterious effects of glutamate spillover are minimized in four ways: First, transporters on the releasing cone bind glutamate; second, Muller cell sheaths occlude the direct path between cone pedicles; third, the position of the transporter reversal potential near the cone voltage operating range reduces current driving force; and fourth, the neural blur caused by conecone glutamate diffusion is less than the optical blur. We consider these factors below.

In rod terminals, transporters completely bind the glutamate released by a strong depolarization (Hasegawa et al., 2006). This is not true for cone terminals, where we demonstrate cone-cone chemical signaling and provide evidence for transporter saturation. In rods, the transporter density is estimated to be 10,000 $\mu \mathrm{m}^{-2}$, which is close to a maximum (Hasegawa et al., 2006). Using this density, the upper bound on the number of transporter channels that could be fitted on the cone terminal is 200,000 (terminal area: $\sim 20 \mu \mathrm{m}^{2}$ ). Two hundred thousand transporters would still not be enough to completely sequester the transmitter released during the synchronous fusion of $100-$ 200 cone vesicles (0.25-1 million glutamate molecules, assuming 2500-5000 per vesicle) at the end of a light pulse (Jackman et al., 2009), given that glutamate transporters are fast-binding but slow-cycling (cycle time: $\sim 70 \mathrm{~ms}$ ) (Wadiche et al., 1995; Otis and Jahr, 1998; Wadiche and Kavanaugh, 1998; Auger and Attwell, 2000). The shape of the cone terminal differs from that of the rod, which may also lessen the likelihood of transmitter recapture by cones. At rod terminals, postsynaptic processes containing receptors are inserted into membrane invaginations where transmitter is released (Sterling and Matthews, 2005). At cone terminals, transmitter is released into invaginations, but must reach the contacts of postsynaptic bipolar cells, most of which carpet the base of the terminal (Missotten, 1965). Once at the base, transmitter diffusion into the OPL neuropil is not restricted.

After eluding transporters on the releasing cone, glutamate must bypass the Muller cell sheaths that insert between terminals. In the primate fovea, the processes from three Muller cells, on average, expand to ensheath each cone terminal (Burris et al., 2002). Glutamate might diffuse through the sheaths at points of overlap, but we agree with Burris et al. (2002) that the amount of flux over this direct path is probably miniscule since the sheath presents an estimated 500,000 transporters to each cone. Sheathes end at the bottom of the cone terminal (Burris et al., 2002; their Figs. 3A,8 A). According to Burris et al. (2002), glutamate that diffuses deep $(>0.5 \mu \mathrm{m})$ into the neuropil encounters only Muller cell trunks, which should not impede lateral spillover. Cone transmitter is thought to reach AMPA receptors at desmosome-like junctions on horizontal cells that are $1 \mu \mathrm{m}$ beneath the cone terminal (Haverkamp et al., 2000). In this context, the calculated diffusion radius of $1.56 \pm 0.40 \mu \mathrm{m}$ for cone-cone signaling is consistent with the flow of transmitter into the neuropil below and between the edges of adjacent terminals.

When glutamate binds to an available acceptor cone transporter, an anion channel is opened. The amplitude of the resulting inward current is minimized under physiological conditions both by the negative transporter current reversal potential $(\sim-30 \mathrm{mV})$ relative to the cone voltage operating range $(-70-$ $-45 \mathrm{mV}$ ) and by the shallow current-voltage relationship of the transporter near the reversal potential (Figs. $2 B, D, 5 A, B$ ). Neuronal membrane $\mathrm{Cl}^{-}$gradients are often actively maintained by $\mathrm{Cl}^{-}$transporters, which may be regulated (Rivera et al., 1999). A more positive $\mathrm{Cl}^{-}$reversal potential would increase the magnitude of cone-cone excitation, whereas a more negative reversal potential might lead to cone-cone inhibition.

Finally, glutamate crosstalk can add neural blur to the first stage of vision. Similar to the neural blur introduced by electrical coupling (Hornstein et al., 2004; Li and DeVries, 2004), the effects of chemical transmission are restricted to neighboring cones, and thus fall within the point spread function of the eye's optics (Campbell and Gubisch, 1966). Therefore, cone-cone transmission should have a minimal effect on visual acuity.

In conclusion, glutamatergic crosstalk between mammalian cones occurs in the intact retina and is regulated by light. Acting via crosstalk, a strong light stimulus changes cone membrane current by $\sim 5 \mathrm{pA}$. For comparison, cone-cone gap junctions mediate a 12-14 pA current under similar conditions ( $\mathrm{Li}$ and DeVries, 2004). Spatially, crosstalk is limited to neighboring cones, and is thus within the point spread function of the eye's optics. Crosstalk could mediate a form of predictive coding that would enhance the cone response to the front edge of a moving dark bar on a light background. Glutamate could also potentially reach receptors on bipolar cells that contact neighboring cones and, in this case, spillover would create an alternative signaling pathway in the OPL.

\section{References}

Agulhon C, Fiacco TA, McCarthy KD (2010) Hippocampal short- and longterm plasticity are not modulated by astrocyte $\mathrm{Ca} 2+$ signaling. Science 327:1250-1254.

Akaike N (1996) Gramicidin perforated patch recording and intracellular chloride activity in excitable cells. Prog Biophys Mol Biol 65:251-264.

Auger C, Attwell D (2000) Fast removal of synaptic glutamate by postsynaptic transporters. Neuron 28:547-558.

Bader CR, Bertrand D, Schwartz EA (1982) Voltage-activated and calciumactivated currents studied in solitary rod inner segments from the salamander retina. J Physiol 331:253-284.

Barbour B, Brew H, Attwell D (1991) Electrogenic uptake of glutamate and aspartate into glial cells isolated from the salamander (Ambystoma) retina. J Physiol 436:169-193.

Barnes S, Hille B (1989) Ionic channels of the inner segment of tiger salamander cone photoreceptors. J Gen Physiol 94:719-743.

Barrow AJ, Wu SM (2009) Low-conductance HCN1 ion channels augment the frequency response of rod and cone photoreceptors. J Neurosci 29:5841-5853.

Berry MJ 2nd, Brivanlou IH, Jordan TA, Meister M (1999) Anticipation of moving stimuli by the retina. Nature 398:334-338.

Burris C, Klug K, Ngo IT, Sterling P, Schein S (2002) How Muller glial cells in macaque fovea coat and isolate the synaptic terminals of cone photoreceptors. J Comp Neurol 453:100-111.

Calkins DJ, Tsukamoto Y, Sterling P (1996) Foveal cones form basal as well as invaginating junctions with diffuse ON bipolar cells. Vision Res 36:3373-3381. 
Campbell FW, Gubisch RW (1966) Optical quality of the human eye. J Physiol 186:558-578.

Chun MH, Grünert U, Martin PR, Wässle H (1996) The synaptic complex of cones in the fovea and in the periphery of the macaque monkey retina. Vision Res 36:3383-3395.

Danbolt NC (2001) Glutamate uptake. Prog Neurobiol 65:1-105.

DeVries SH (2000) Bipolar cells use kainate and AMPA receptors to filter visual information into separate channels. Neuron 28:847-856.

DeVries SH (2001) Exocytosed protons feedback to suppress the Ca2 + current in mammalian cone photoreceptors. Neuron 32:1107-1117.

DeVries SH, Schwartz EA (1999) Kainate receptors mediate synaptic transmission between cones and 'Off' bipolar cells in a mammalian retina. Nature 397:157-160.

DeVries SH, Qi X, Smith R, Makous W, Sterling P (2002) Electrical coupling between mammalian cones. Curr Biol 12:1900-1907.

DeVries SH, Li W, Saszik S (2006) Parallel processing in two transmitter microenvironments at the cone photoreceptor synapse. Neuron 50:735-748.

Dowling JE, Boycott BB (1966) Organization of the primate retina: electron microscopy. Proc R Soc Lond B Biol Sci 166:80-111.

Eliasof S, Arriza JL, Leighton BH, Kavanaugh MP, Amara SG (1998) Excitatory amino acid transporters of the salamander retina: identification, localization, and function. J Neurosci 18:698-712.

Hasegawa J, Obara T, Tanaka K, Tachibana M (2006) High-density presynaptic transporters are required for glutamate removal from the first visual synapse. Neuron 50:63-74.

Haverkamp S, Grünert U, Wässle H (2000) The cone pedicle, a complex synapse in the retina. Neuron 27:85-95.

Helgen KM, Cole FR, Helgen LE, Wilson DE (2009) Generic revision in the holarctic ground squirrel genus Spermophilus. J Mammalogy 90:270-305.

Hornstein EP, Verweij J, Schnapf JL (2004) Electrical coupling between red and green cones in primate retina. Nat Neurosci 7:745-750.

Hosoi N, Arai I, Tachibana M (2005) Group III metabotropic glutamate receptors and exocytosed protons inhibit L-type calcium currents in cones but not in rods. J Neurosci 25:4062-4072.

Hosoya T, Baccus SA, Meister M (2005) Dynamic predictive coding by the retina. Nature 436:71-77.

Jackman SL, Choi SY, Thoreson WB, Rabl K, Bartoletti TM, Kramer RH (2009) Role of the synaptic ribbon in transmitting the cone light response. Nat Neurosci 12:303-310.

Kolb H, Jones J (1985) Electron microscopy of Golgi-impregnated photoreceptors reveals connections between red and green cones in the turtle retina. J Neurophysiol 54:304-317.

Kolb H, Goede P, Roberts S, McDermott R, Gouras P (1997) Uniqueness of the $\mathrm{S}$-cone pedicle in the human retina and consequences for color processing. J Comp Neurol 386:443-460.

Kraft TW (1988) Photocurrents of cone photoreceptors of the goldenmantled ground squirrel. J Physiol 404:199-213.

Lasansky A (1973) Organization of the outer synaptic layer in the retina of the larval tiger salamander. Philos Trans R Soc Lond B Biol Sci 265:471-489.

Lee SC, Telkes I, Grünert U (2005) S-cones do not contribute to the OFFmidget pathway in the retina of the marmoset, Callithrix jacchus. Eur J Neurosci 22:437-447.

Li W, DeVries SH (2004) Separate blue and green cone networks in the mammalian retina. Nat Neurosci 7:751-756.

Li W, Keung JW, Massey SC (2004) Direct synaptic connections between rods and OFF cone bipolar cells in the rabbit retina. J Comp Neurol $474: 1-12$.

Li W, Chen S, DeVries SH (2010) A fast rod photoreceptor signaling pathway in the mammalian retina. Nat Neurosci 13:414-416.

Mariani AP, Lasansky A (1984) Chemical synapses between turtle photoreceptors. Brain Res 310:351-354.

Missotten L (1965) The ultrastructure of the human retina. Brussels: Arscia Uitgaven N.V.

Nakajima Y, Iwakabe H, Akazawa C, Nawa H, Shigemoto R, Mizuno N, Nakanishi S (1993) Molecular characterization of a novel retinal metabotropic glutamate receptor mGluR6 with a high agonist selectivity for L-2-amino-4-phosphonobutyrate. J Biol Chem 268:11868-11873.

Nakamura Y, Kataoka K, Ishida M, Shinozaki H (1993) (2S,3S,4R)-2(carboxycyclopropyl)glycine, a potent and competitive inhibitor of both glial and neuronal uptake of glutamate. Neuropharmacology 32:833-837.

Nielsen TA, DiGregorio DA, Silver RA (2004) Modulation of glutamate mobility reveals the mechanism underlying slow-rising AMPAR EPSCs and the diffusion coefficient in the synaptic cleft. Neuron 42:757-771.

Nikonov SS, Brown BM, Davis JA, Zuniga FI, Bragin A, Pugh EN Jr, Craft CM (2008) Mouse cones require an arrestin for normal inactivation of phototransduction. Neuron 59:462-474.

Normann RA, Perlman I, Kolb H, Jones J, Daly SJ (1984) Direct excitatory interactions between cones of different spectral types in the turtle retina. Science 224:625-627.

Normann RA, Perlman I, Daly SJ (1985) Mixing of color signals by turtle cone photoreceptors. J Neurophysiol 54:293-303.

Otis TS, Jahr CE (1998) Anion currents and predicted glutamate flux through a neuronal glutamate transporter. J Neurosci 18:7099-7110.

Otis TS, Kavanaugh MP (2000) Isolation of current components and partial reaction cycles in the glial glutamate transporter EAAT2. J Neurosci 20:2749-2757.

Palmer MJ, Hull C, Vigh J, von Gersdorff H (2003) Synaptic cleft acidification and modulation of short-term depression by exocytosed protons in retinal bipolar cells. J Neurosci 23:11332-11341.

Parpura V, Basarsky TA, Liu F, Jeftinija K, Jeftinija S, Haydon PG (1994) Glutamate-mediated astrocyte-neuron signalling. Nature 369:744-747.

Pasti L, Volterra A, Pozzan T, Carmignoto G (1997) Intracellular calcium oscillations in astrocytes: a highly plastic, bidirectional form of communication between neurons and astrocytes in situ. J Neurosci 17:7817-7830.

Picaud S, Larsson HP, Wellis DP, Lecar H, Werblin F (1995a) Cone photoreceptors respond to their own glutamate release in the tiger salamander. Proc Natl Acad Sci U S A 92:9417-9421.

Picaud SA, Larsson HP, Grant GB, Lecar H, Werblin FS (1995b) Glutamate-gated chloride channel with glutamate-transporter-like properties in cone photoreceptors of the tiger salamander. J Neurophysiol 74:1760-1771.

Rillich K, Gentsch J, Reichenbach A, Bringmann A, Weick M (2009) Light stimulation evokes two different calcium responses in Muller glial cells of the guinea pig retina. Eur J Neurosci 29:1165-1176.

Rivera C, Voipio J, Payne JA, Ruusuvuori E, Lahtinen H, Lamsa K, Pirvola U, Saarma M, Kaila K (1999) The K+/CI- co-transporter KCC2 renders GABA hyperpolarizing during neuronal maturation. Nature 397:251255.

Rowan MJ, Ripps H, Shen W (2010) Fast glutamate uptake via EAAT2 shapes the cone-mediated light offset response in bipolar cells. J Physiol 588:3943-3956.

Sarantis M, Everett K, Attwell D (1988) A presynaptic action of glutamate at the cone output synapse. Nature 332:451-453.

Sarthy VP, Pignataro L, Pannicke T, Weick M, Reichenbach A, Harada T, Tanaka K, Marc R (2005) Glutamate transport by retinal Muller cells in glutamate/aspartate transporter-knockout mice. Glia 49:184-196.

Scholes JH (1975) Colour receptors, and their synaptic connexions, in the retina of a cyprinid fish. Philos Trans R Soc Lond B Biol Sci 270:61-118.

Slaughter MM, Miller RF (1983) An excitatory amino acid antagonist blocks cone input to sign-conserving second-order retinal neurons. Science 219:1230-1232.

Sterling P, Matthews G (2005) Structure and function of ribbon synapses. Trends Neurosci 28:20-29.

Tachibana M, Kaneko A (1988) L-glutamate-induced depolarization in solitary photoreceptors: a process that may contribute to the interaction between photoreceptors in situ. Proc Natl Acad Sci U S A 85:5315-5319.

Thoreson WB, Bryson EJ (2004) Chloride equilibrium potential in salamander cones. BMC Neurosci 5:53.

Vandenberg RJ, Mitrovic AD, Johnston GA (1998) Serine-O-sulphate transport by the human glutamate transporter, EAAT2. Br J Pharmacol 123:1593-1600.

Veruki ML, Mørkve SH, Hartveit E (2006) Activation of a presynaptic glutamate transporter regulates synaptic transmission through electrical signaling. Nat Neurosci 9:1388-1396.

Wadiche JI, Kavanaugh MP (1998) Macroscopic and microscopic properties of a cloned glutamate transporter/chloride channel. J Neurosci 18:7650-7661.

Wadiche JI, Arriza JL, Amara SG, Kavanaugh MP (1995) Kinetics of a human glutamate transporter. Neuron 14:1019-1027.

West RW, Dowling JE (1975) Anatomical evidence for cone and rod-like receptors in the gray squirrel, ground squirrel, and prairie dog retinas. J Comp Neurol 159:439-460. 